Gut and Liver, Vol. 13, No. 1, January 2019, pp. 40-47

\title{
Continuous Infusion versus Intermittent Dosing with Pantoprazole for Gastric Endoscopic Submucosal Dissection
}

\author{
Bong Eun Lee, Gwang Ha Kim, Geun Am Song, Jong Hun Seo, Hye Kyung Jeon, Dong Hoon Baek, and Dong Uk Kim \\ Department of Internal Medicine, Biomedical Research Institute, Pusan National University Hospital, Pusan National University School of \\ Medicine, Busan, Korea
}

Background/Aims: Proton pump inhibitors are widely used to prevent gastric endoscopic submucosal dissection (ESD)related bleeding, but no standard administration regimens have been established. We aimed to prospectively compare the effects of continuous infusion and intermittent dosing with pantoprazole on preventing gastric ESD-related bleeding. Additionally, we analyzed the risk factors for bleeding. Methods: From April 2012 to May 2013, patients with a gastric epithelial neoplasm scheduled for ESD in the Pusan National University Hospital were randomly assigned to one of two groups according to the pantoprazole administration regimen (continuous infusion or intermittent dosing). The primary outcomes measured were intra- and postprocedural bleeding events. Results: The final analysis included 401 patients. The rate of significant intraprocedural bleeding was $25.4 \%$ in the $C$ group and $24.0 \%$ in the I group, with no significant difference $(p=0.419)$. In addition, there was no significant difference in the postprocedural bleeding rate between the $\mathrm{C}$ and I groups ( $11.7 \%$ vs $10.2 \%, p=0.374)$. Multivariate analysis showed that intraprocedural bleeding was associated with the proximal tumor location, the presence of fibrosis, and the size of the resected specimen, whereas postprocedural bleeding was associated with the size of the resected specimen and the procedure/coagulation time. Conclusions: Intermittent dosing with pantoprazole is sufficient and cost-effective for the prevention of gastric ESD-related bleeding. Operators should consider tumor characteristics when planning ESD to minimize the risk of intraprocedural bleeding, and patients with large iatrogenic ulcers should be carefully monitored for postprocedural bleeding. (Gut Liver 2019;13:40-47)

Key Words: Gastrointestinal hemorrhage; Proton pump in- hibitors; Endoscopic mucosal resection; Stomach neoplasms

\section{INTRODUCTION}

Endoscopic submucosal dissection (ESD) is now established as a curative treatment for gastric epithelial neoplasms such as early gastric cancer (EGC) and adenoma. Compared to endoscopic mucosal resection (EMR), ESD enables en bloc resection for relatively large lesions with or without ulcer/fibrosis. However, ESD is associated with higher risk of adverse events such as bleeding or perforation because it creates a larger and deeper ulcer. ${ }^{1}$ Since bleeding is the most common adverse event, it is important to prevent and control the bleeding.

ESD-related bleeding is divided into intraprocedural and postprocedural bleeding. Intraprocedural bleeding rates have been reported to vary from $22.6 \%$ to $90.6 \%$ according to the different definition of the bleeding, ${ }^{1-3}$ while postprocedural bleeding rates range from $1.3 \%$ to $11.9 \%{ }^{4-10}$ Although $50 \%$ to $70 \%$ of bleeding events are observed within 48 hours after ESD, bleeding can present as late as 14 days. ${ }^{10,11}$ Intraprocedural bleeding is inevitable, and primarily affected by endoscopic techniques ${ }^{12}$ and tumor characteristics such as proximal location and large size. ${ }^{2,13-15}$ As postprocedural bleeding often occurs due to gastric acid-induced dissolution of fibrin clots, antisecretory drugs such as proton pump inhibitors (PPIs) or histamine-2 receptor antagonists (H2RAs) have been routinely administered to prevent bleeding. A meta-analysis of five randomized controlled trials comparing PPIs and H2RAs revealed that PPIs were significantly superior in preventing postprocedural bleeding, ${ }^{16}$ and a Japanese multicenter survey regarding patient management after gastric ESD reported that all participating hospitals used a PPI. ${ }^{5}$ In fact, PPIs currently represent the standard to prevent gastric ESD-related bleeding.

\footnotetext{
Correspondence to: Geun Am Song

Department of Internal Medicine, Biomedical Research Institute, Pusan National University Hospital, Pusan National University School of Medicine, 179 Gudeok-ro, Seo-gu, Busan 49241, Korea

Tel: +82-51-240-7869, Fax: +82-51-244-8180, E-mail: gasong@pusan.ac.kr

Received on May 17, 2018. Revised on July 20, 2018. Accepted on July 23, 2018. Published online December 14, 2018

pISSN 1976-2283 eISSN 2005-1212 https://doi.org/10.5009/gnl18222

@ This is an Open Access article distributed under the terms of the Creative Commons Attribution Non-Commercial License (http://creativecommons.org/licenses/by-nc/4.0) which permits unrestricted non-commercial use, distribution, and reproduction in any medium, provided the original work is properly cited.
} 
However, there is no consensus regarding the optimal PPI administration in patients undergoing gastric ESD, and individual approaches are applied in each institute. We mainly aimed to prospectively compare the effects of continuous infusion and intermittent dosing of pantoprazole for preventing gastric ESDrelated bleeding. Additionally, we analyzed the risk factors for bleeding during and after ESD.

\section{MATERIALS AND METHODS}

\section{Study population}

We conducted a prospective, randomized controlled trial between April 2012 and May 2013, enrolling patients with previously diagnosed gastric adenoma or EGC who were scheduled for ESD in Pusan National University Hospital. Written informed consent was obtained from all participants before ESD, and this study was approved by the Institutional Review Board of Pusan National University Hospital (1204-030-001). Our research was registered at the Clinical Trial Registration sites in Korea (http:// cris.nih.go.kr) as KCT0000391.

\section{Inclusion and exclusion criteria}

We performed ESD for patients with gastric adenoma or EGC according to the expanded criteria proposed by Gotoda et al. ${ }^{17}$ Exclusion criteria were as follows: (1) previous history of upper gastrointestinal surgery or vagotomy; (2) known hypersensitivity to pantoprazole; (3) current (within 7 days prior to the procedure) use of antiplatelet agents, anticoagulants, or steroids; (4) current use of PPIs or H2RAs; (5) physical status III or IV according to the classification put forth by the American Society of Anesthesiologists, or severe comorbidity; and (6) recurrent lesion.

\section{Study design}

Before ESD, each patient was randomly assigned to receive continuous pantoprazole infusion (C-group) or intermittent pantoprazole dosing (I-group), according to a randomization table generated using Excel 2003 (Microsoft Corp., Redmond, WA, USA).

Fig. 1 shows the study protocol. In the C-group, pantoprazole $80 \mathrm{mg}$ was administered intravenously at least 2 hours before ESD, followed by continuous intravenous administration (8 mg/ hr) for 2 days. In the I-group, intravenous pantoprazole $40 \mathrm{mg}$ was administered twice a day for 2 days, with the first dose administered at least 2 hours before ESD. Starting on postoperative day 3, pantoprazole $40 \mathrm{mg}$ was administered orally for 8 weeks.

\section{ESD procedure}

ESD was performed by two experienced endoscopists who had conducted gastric ESD more than 5 years (G.A.S and G.H.K) according to the standard ESD techniques. ${ }^{18}$ ESD was performed using a single channel endoscope (GIF-H260, Q260; Olympus Optical Co., Ltd., Tokyo, Japan) with a dual knife (KD-650L; Olympus Medical Systems, Tokyo, Japan) and an insulationtipped knife (KD610L; Olympus Medical Systems). A VIO 300D device (Erbe, Tübingen, Germany) was used as an electrosurgical unit. As first, circumferential markings were placed around the lesion using an argon plasma coagulation probe. Next, saline solution with a small amount of epinephrine and indigo carmine was injected into the submucosa. After lifting the lesion, a circumferential incision was made using the fractionated cutting settings (Endocut I mode at Effect 3, duration 3, interval 2). Subsequent submucosal dissection using the swift coagulation mode (Effect 4, output $100 \mathrm{~W}$ ) achieved complete removal of the lesion. Throughout the procedure, submucosal fluid injection was repeated as needed. If active bleeding or visible vessels were noted during ESD, electrocoagulation was performed using hot biopsy forceps or Coagrasper (FD-410LR; Olympus Medical Systems) with the soft coagulation mode (Effect 6, output $100 \mathrm{~W}$ ).

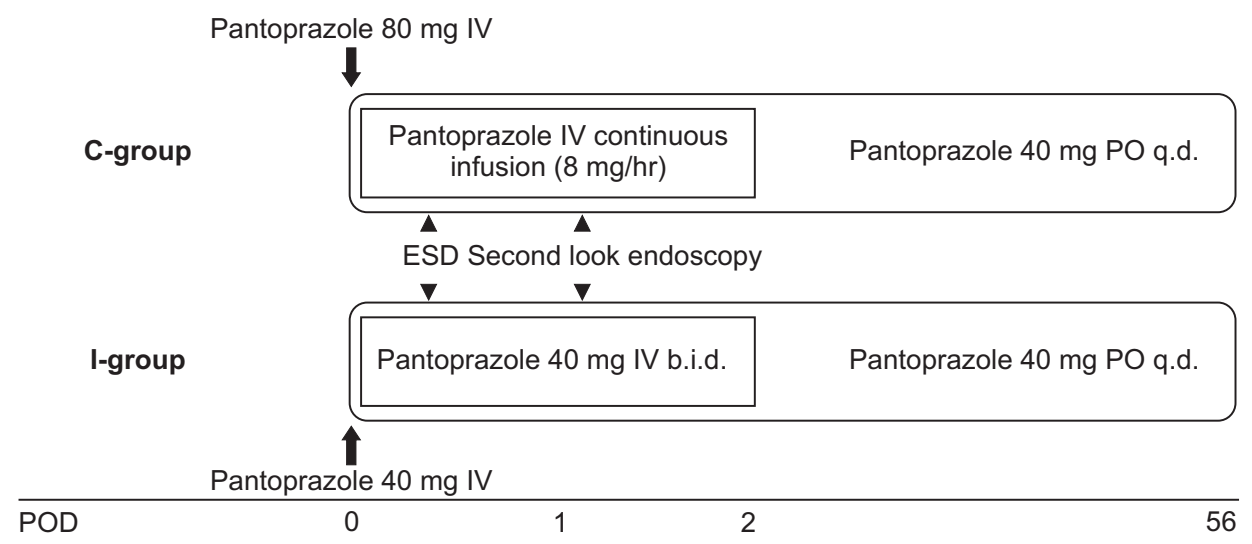

Fig. 1. Study design to assess the effect of pantoprazole administration regimen regarding the prevention of intra- and postprocedural bleeding in patients who underwent endoscopic submucosal dissection (ESD) for a gastric epithelial neoplasm. Patients were randomly assigned to one of two groups depending on the pantoprazole administration regimen, namely, continuous infusion (C-group) or intermittent dosing (I-group). POD, postoperative day; IV, intravenous; PO, per oral; q.d., once a day; b.i.d., twice a day. 
Before ESD completion, prophylactic electrocoagulation was performed for all exposed visible vessels, regardless of the presence or absence of bleeding.

\section{Monitoring of bleeding events and second-look endos- copy}

Regular vital check-ups and daily monitoring for bleeding were conducted during hospitalization. Second-look endoscopy (SLE) was performed on postoperative day 1, and endoscopic hemostasis was done for bleeding ulcers and non-bleeding exposed vessels.

\section{Outcome measurement and definitions}

The primary outcome was postprocedural bleeding. Postprocedural bleeding was defined as follows with reference to previous articles: $:^{13,19}(1)$ presence of bleeding signs (hematemesis, melena, or hematochezia), (2) unstable vital signs (hypotension or tachycardia), (3) >2 g/dL decrease in hemoglobin levels, or (4) hemorrhage confirmed on SLE (active bleeding or presence of blood or clots in the stomach). Postprocedural bleeding was classified as "early" or "delayed" if it occurred within or later than 48 hours after ESD, respectively. Intraprocedural bleeding with use of hemoclips during ESD for hemostasis and status of post-ESD ulcer on SLE were measured as secondary outcomes. Intraprocedural bleeding was graded by an operator right after ESD procedure as follows: grade 0 , no visible bleeding; grade 1, trivial bleeding that resolved spontaneously or could be easily controlled by a single session of hemocoagulation; grade 2, minor bleeding that could be controlled by multiple sessions of hemocoagulation or easily controlled by hemoclips; grade 3 , major bleeding needing multiple hemoclips. Intraprocedural bleeding of grade 0 or 1 were further classified as insignificant, while those of grade 2 or 3 were classified as significant. Use of hemoclips during ESD for hemostasis was documented in the ESD report. Post-ESD ulcers noted on SLE were further classified as having high risk (Forrest type I or IIa) or low risk for bleeding (Forrest type IIb, IIc, or III), according to the Forrest classification. ${ }^{20}$

\section{Clinicopathologic data}

The patients' medical records were reviewed to extract demographic data. Atrophic gastritis was endoscopically classified as "open" or "closed" types according to Kimura-Takemoto classification. ${ }^{21}$ The following tumor characteristics were investigated: multiplicity, macroscopic type, tumor location, presence of ulcer or fibrosis, histology, invasion depth, tumor size, and resected specimen dimensions (size and surface area). The surface area of the resected specimen was calculated by multiplying the maximum diameter by its perpendicular diameter. Total procedural time from intubation to withdrawal of the endoscope, as well as the prophylactic coagulation time were examined. Clinical outcomes including rates of en bloc resection, complete resection, and curative resection were investigated.

\section{Sample size calculation}

We hypothesized that gastric ESD-related bleeding rates would not differ significantly with the pantoprazole administration regimen (C-group vs I-group). That is, we supposed that Igroup would not be inferior to C-group in the aspects of gastricESD related bleeding. According to data from the previous ESD registry (576 patients from January 2011 to December 2011) at our institute, we expected a 7\% and 11\% post-ESD bleeding rate in the C- and I-group, respectively. The power calculation using a 5\% significance level and statistical power of 80\% indicated a required sample size of 425 patients per each group, which was not feasible for a prospective randomized study in a single center. We reviewed the literature and found that previous studies on this topic typically enrolled approximately 100 patients. In this context, and considering the volume of patients in our hospital, we planned to include 400 patients (200 per each group). Therefore, we resolved to enroll 440 patients (220 per each group), expecting a 10\% withdrawal rate.

\section{Statistical analysis}

Continuous variables were expressed as mean \pm standard deviation or range, while categorical variables were presented as frequencies with percentages. In the univariate analysis, Student t-tests and analysis of variance were used to compare continuous variables, and the chi-square and Fisher exact tests were used to compare categorical variables. Multivariate analysis was performed using forward logistic regression, and the results were expressed as odds ratio (ORs) with 95\% confidence interval (CIs). Statistical analyses were performed using SPSS version 21.0 (SPSS Inc., Chicago, IL, USA). p-values of less than 0.05 were considered to indicate statistical significance.

\section{RESULTS}

\section{Baseline characteristics and clinical outcomes}

Among the 440 patients enrolled, 39 were excluded because of incorrect PPI dosing $(n=30)$, cancellation of ESD $(n=5)$, postprocedural aspirin use $(n=1)$, and insufficient data for analysis $(n=3)$ (Fig. 2). A total of 401 patients were included in the final analysis (mean age, 64.6 years; age range, 27 to 87 years), among whom 274 (68.3\%) were men. Thirty-eight patients (9.5\%) had multiple lesions with a total of 443 lesions resected. After ESD, pathologic diagnoses were confirmed as follows: 197 EGCs, 231 adenomas (178 of low-grade dysplasia, 53 of high-grade dysplasia), 14 of chronic gastritis, and one advanced gastric cancer. Macroscopically, elevated lesions were most frequent (232 lesions, 52.4\%), while 142 (32.0\%) and 69 (15.6\%) showed depressed and flat profile, respectively. Significant intraprocedural bleeding was observed in 99 patients (24.7\%), and the postprocedural bleeding rate was $11.0 \%$ (early bleeding, 8.7\%; delayed bleeding, 2.5\%). The rates of en bloc resection, 
complete resection, and curative resection were 98.4\%, 92.1\%, and $88.7 \%$, respectively.

\section{Comparison of clinicopathologic features and outcomes between the $\mathbf{C}$-group and I-group}

Tables 1 and 2 summarizes the clinicopathologic features and outcomes of the C-group ( $n=205)$ and I-group ( $n=196)$. While the I-group showed higher positivity for Helicobacter pylori (75.0\% vs $63.9 \% ; p=0.011)$, the severity of atrophic gastritis was not different between two groups $(\mathrm{p}=0.478)$. And there were no significant differences between two groups regarding other clinicopathologic characteristics and outcomes.

With regard to ESD-related bleeding, significant intraprocedural bleeding was observed in 52 patients $(25.4 \%)$ in the Cgroup and $47(24.0 \%)$ in the I-group, with no statistical significance $(p=0.419)$. Similarly, there were no significant differences in postprocedural bleeding rates between the C-group and Igroup (postprocedural bleeding rate: $11.7 \%$ vs $10.2 \%, p=0.374$; early bleeding rate: $10.2 \%$ vs $7.1 \%, p=0.178$; delayed bleeding rate: $2.0 \%$ vs $3.1 \%, \mathrm{p}=0.348$ ). Post-ESD ulcers on SLE did not differ between the two groups $(\mathrm{p}=0.268)$. All patients with postprocedural bleeding were successfully managed by endoscopic hemostasis.

\section{Risk factors for intraprocedural bleeding}

In univariate analysis, significant intraprocedural bleeding was associated with proximal location $(\mathrm{p}<0.001)$, presence of fibrosis $(\mathrm{p}=0.001)$, submucosal invasion $(\mathrm{p}=0.010)$, and larger resected specimen size/area $(\mathrm{p}<0.001)$ (Table 3$)$. On multivariate analysis, significant correlation with intraprocedural bleeding was noted for proximal location (relative to location in the middle third: OR, 2.694; 95\% CI, 1.484 to 4.889 ; relative to location in the upper third: OR, 8.971; 95\% CI, 4.300 to 18.713 ), presence of fibrosis (OR, 2.286; 95\% CI, 1.081 to 4.832), and larger resected specimen area (OR, 1.101; 95\% CI, 1.066 to 1.136) (Table 4).

Table 1. Clinicopathological Characteristics

\begin{tabular}{|c|c|c|c|}
\hline Characteristics & $\begin{array}{l}\text { C-group } \\
(\mathrm{n}=205)\end{array}$ & $\begin{array}{l}\text { I-group } \\
(\mathrm{n}=196)\end{array}$ & p-value \\
\hline Age, yr & $64.8 \pm 8.9$ & $64.3 \pm 9.1$ & 0.581 \\
\hline Male sex & $144(70.2)$ & $130(66.3)$ & 0.231 \\
\hline BMI, $\mathrm{kg} / \mathrm{m}^{2}$ & $24.0 \pm 3.7$ & $23.3 \pm 3.3$ & 0.066 \\
\hline Comorbidities & $91(44.4)$ & $84(42.9)$ & 0.417 \\
\hline Helicobacter pylori positivity & $131(63.9)$ & 147 (75.0) & 0.011 \\
\hline Open type-AG & $31(15.1)$ & $31(15.8)$ & 0.478 \\
\hline Multiplicity & $19(9.3)$ & $19(9.7)$ & 0.510 \\
\hline Tumor location & & & 0.241 \\
\hline Upper third & $30(14.6)$ & $19(9.7)$ & \\
\hline Middle third & $48(23.4)$ & $55(28.1)$ & \\
\hline Lower third & $127(62.0)$ & $122(62.2)$ & \\
\hline Ulceration & $12(5.9)$ & $10(5.1)$ & 0.457 \\
\hline Submucosal fibrosis & $19(9.3)$ & $25(12.8)$ & 0.169 \\
\hline Carcinoma & $93(45.4)$ & $98(50.0)$ & 0.204 \\
\hline Submucosal invasion & $18(8.8)$ & $20(10.2)$ & 0.376 \\
\hline Tumor size, $\mathrm{cm}$ & $1.6 \pm 1.1$ & $1.6 \pm 1.0$ & 0.239 \\
\hline Resected specimen size, cm & $3.5 \pm 1.5$ & $3.6 \pm 1.6$ & 0.722 \\
\hline Resected specimen area, $\mathrm{cm}^{2}$ & $10.4 \pm 8.4$ & $11.0 \pm 9.4$ & 0.487 \\
\hline Procedural time, min & $27.5 \pm 27.0$ & $26.0 \pm 23.1$ & 0.573 \\
\hline Coagulation time, min & $8.4 \pm 6.1$ & $8.4 \pm 6.2$ & 0.952 \\
\hline
\end{tabular}

Data are presented as mean \pm SD or number (\%).

C-group, continuous pantoprazole infusion group; I-group, intermittent pantoprazole dosing group; BMI, body mass index; AG, atrophic gastritis.

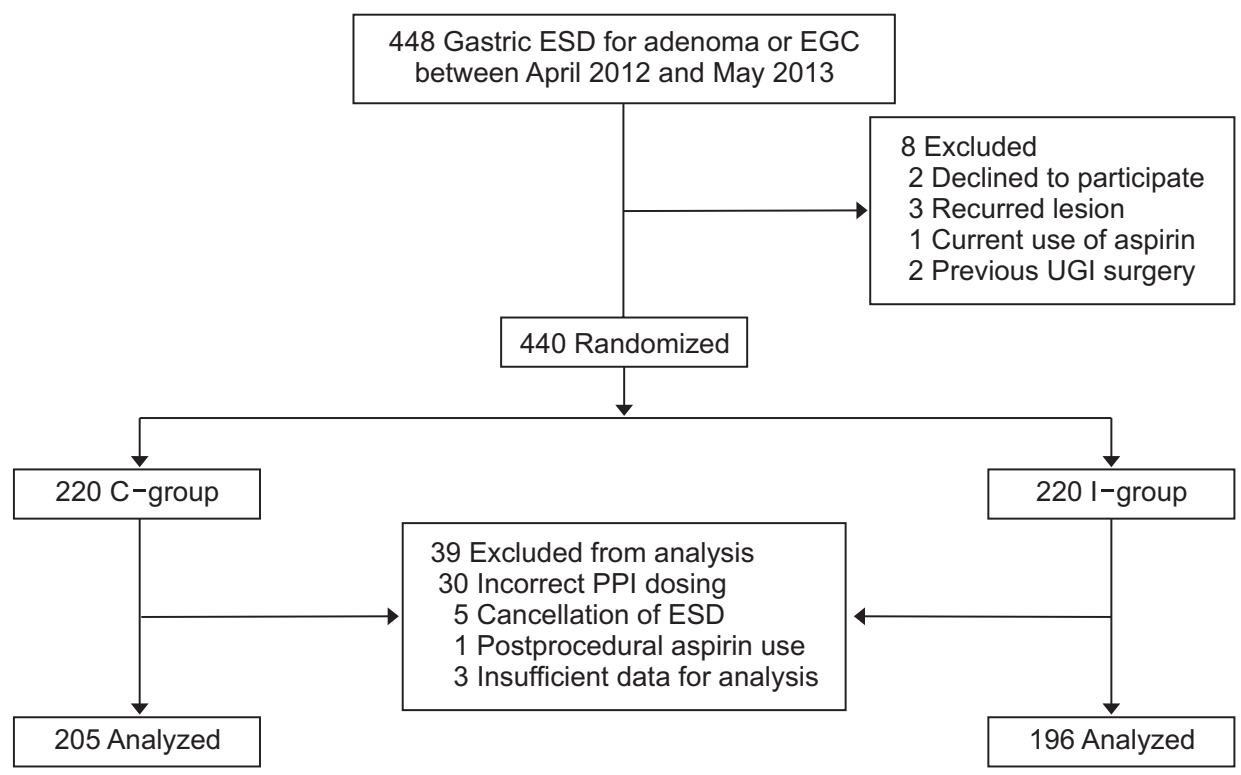

Fig. 2. Flow diagram of enrollment, intervention allocation, and exclusions.

ESD, endoscopic submucosal dissection; EGC, early gastric cancer; UGI, upper gastrointestinal; C-group, continuous pantoprazole infusion group; I-group, intermittent pantoprazole dosing group; PPI, proton pump inhibitor. 


\section{Risk factors for early bleeding}

Early bleeding was associated with presence of fibrosis ( $p=0.026)$, larger resected specimen size/area $(p=0.017 / p=0.001)$, and longer procedural/coagulation time $(p=0.001 / p=0.001)$ (Table 5). Although the occurrence of significant intraprocedural bleeding did not influence the incidence of early bleeding, hemoclips were frequently used during ESD in patients with early bleeding $(\mathrm{p}=0.018)$.

\section{Risk factors for delayed bleeding}

Delayed bleeding was associated with larger resected specimen size/area $(p<0.001$ and $p=0.007$, respectively) and longer procedural/coagulation time $(\mathrm{p}=0.019 / \mathrm{p}=0.001)$ (Table 6). The occurrence of significant intraprocedural bleeding or early bleeding was not related with the incidence of delayed bleeding ( $p=0.466$ and $p=0.603$, respectively). The mean time to onset of delayed bleeding was 10.4 days (range, 3 to 19 days).

\section{DISCUSSION}

In the present study, continuous infusion of pantoprazole offered no additional benefit over intermittent administration in the prevention of gastric ESD-related bleeding. Moreover, postESD ulcers on SLE also did not show differences between two methods when classifying them into high or low risk for bleeding.

Gastric acid inhibits platelet aggregation and blood coagulation. Fibrinolytic activity through pepsin activation is also dependent on gastric $\mathrm{pH}$. Thus, acid inhibition is important to stabilize blood clots and prevent ulcer bleeding. High-dose PPI regimens (80-mg intravenous bolus followed by a 72-hour continuous intravenous infusion of $8 \mathrm{mg} / \mathrm{hr}$ ) have been reported

Table 2. Clinical Outcomes Associated with Continuous and Intermittent Pantoprazole Dosing

\begin{tabular}{lccc}
\hline & $\begin{array}{c}\text { C-group } \\
(\mathrm{n}=205)\end{array}$ & $\begin{array}{c}\text { I-group } \\
(\mathrm{n}=196)\end{array}$ & p-value \\
\hline Intraprocedural bleeding & & & 0.419 \\
$\quad$ Insignificant (grade 0 or 1) & $153(74.6)$ & $149(76.0)$ & \\
$\quad$ Significant (grade 2 or 3) & $52(25.4)$ & $47(24.0)$ & \\
Use of hemoclips & $31(15.1)$ & $27(13.8)$ & 0.405 \\
Early bleeding & $21(10.2)$ & $14(7.1)$ & 0.178 \\
High-risk stigmata on SLE & $22(10.7)$ & $13(6.6)$ & 0.268 \\
Delayed bleeding & $4(2.0)$ & $6(3.1)$ & 0.348 \\
En bloc resection rate & 99.5 & 96.9 & 0.054 \\
Complete resection rate & 93.1 & 93.4 & 0.543 \\
Curative resection rate & 91.2 & 90.8 & 0.519 \\
\hline
\end{tabular}

Data are presented as number (\%) or percentage.

C-group, continuous pantoprazole infusion group; I-group, intermittent pantoprazole dosing group; SLE, second-look endoscopy. to keep gastric $\mathrm{pH}>6.0,{ }^{22-24}$ and a recent guideline recommends high-dose PPI for patients with peptic ulcer bleeding (PUB). ${ }^{25}$ Although the latest Cochrane meta-analysis failed to show superiority of high-dose over lower-dose PPI for PUB, there was little evidence to support the adoption of lower-dose PPI regimens in these patients. ${ }^{26}$ To address the conflicting evidence and lack of consensus regarding optimal use of PPI in patients undergoing gastric ESD, we performed the present trial and concluded that low-dose intermittent administration of pantoprazole (40 mg, twice a day) had adequate efficacy in preventing gastric ESD-

Table 3. Results of the Univariate Analysis of Risk Factors for Intraprocedural Bleeding

\begin{tabular}{|c|c|c|c|}
\hline Variable & $\begin{array}{l}\text { Significant } \\
\text { intraproce- } \\
\text { dural bleed- } \\
\text { ing }(n=99)\end{array}$ & $\begin{array}{l}\text { Insignificant } \\
\text { intraproce- } \\
\text { dural bleed- } \\
\text { ing }(n=302)\end{array}$ & p-value \\
\hline Age, yr & $65.2 \pm 10.0$ & $64.4 \pm 8.7$ & 0.476 \\
\hline Male sex & $72(72.7)$ & 202 (66.9) & 0.169 \\
\hline BMI, $\mathrm{kg} / \mathrm{m}^{2}$ & $23.8 \pm 3.6$ & $23.6 \pm 3.5$ & 0.580 \\
\hline Comorbidities & $58(58.6)$ & $168(55.6)$ & 0.346 \\
\hline Helicobacter pylori positivity & $62(62.6)$ & $216(71.5)$ & 0.063 \\
\hline Open type-AG & $11(11.1)$ & $51(16.9)$ & 0.109 \\
\hline Multiplicity & $12(12.1)$ & $26(8.6)$ & 0.199 \\
\hline Tumor location & & & $<0.001$ \\
\hline Upper third & $30(30.3)$ & $19(6.3)$ & \\
\hline Middle third & 33 (33.3) & $70(23.2)$ & \\
\hline Lower third & $36(36.4)$ & $213(70.5)$ & \\
\hline Carcinoma & $47(47.5)$ & $163(54.0)$ & 0.157 \\
\hline Submucosal invasion & $16(16.2)$ & $22(7.3)$ & 0.010 \\
\hline Ulceration & $8(8.1)$ & $14(4.6)$ & 0.147 \\
\hline Submucosal fibrosis & $20(20.2)$ & $24(7.9)$ & 0.001 \\
\hline Resected specimen size, $\mathrm{cm}$ & $4.6 \pm 1.8$ & $3.2 \pm 1.3$ & $<0.001$ \\
\hline Resected specimen area, $\mathrm{cm}^{2}$ & $16.7 \pm 11.5$ & $8.7 \pm 6.8$ & $<0.001$ \\
\hline Endoscopist & & & 1.000 \\
\hline Endoscopist 1 & $30(24.6)$ & $92(75.4)$ & \\
\hline Endoscopist 2 & 69 (24.7) & 210 (75.3) & \\
\hline
\end{tabular}

Data are presented as mean \pm SD or number $(\%)$.

BMI, body mass index; AG, atrophic gastritis.

Table 4. Results of the Multivariate Analysis of Risk Factors for Intraprocedural Bleeding

\begin{tabular}{llcc}
\hline \multicolumn{1}{c}{ Variable } & $\begin{array}{c}\text { Odds } \\
\text { ratio }\end{array}$ & $\begin{array}{c}95 \% \text { confidence } \\
\text { interval }\end{array}$ & p-value \\
\hline Submucosal invasion & 1.16 & $0.493-2.729$ & 0.734 \\
Resected specimen area $\left(\mathrm{cm}^{2}\right)$ & 1.101 & $1.066-1.136$ & $<0.001$ \\
Presence of fibrosis & 2.286 & $1.081-4.832$ & 0.03 \\
Location (middle third) & 2.694 & $1.484-4.889$ & 0.001 \\
Location (upper third) & 8.971 & $4.300-18.713$ & $<0.001$ \\
\hline
\end{tabular}


Table 5. Results of the Univariate Analysis of Risk Factors for Early Bleeding (within 48 Hours)

\begin{tabular}{|c|c|c|c|}
\hline Variable & $\begin{array}{c}\text { Early } \\
\text { bleeding } \\
(n=35)\end{array}$ & $\begin{array}{l}\text { No early } \\
\text { bleeding } \\
(n=366)\end{array}$ & $\mathrm{p}$-value \\
\hline Age, yr & $64.5 \pm 8.7$ & $64.6 \pm 9.0$ & 0.958 \\
\hline Male sex & $27(77.1)$ & $247(67.5)$ & 0.163 \\
\hline BMI, $\mathrm{kg} / \mathrm{m}^{2}$ & $22.5 \pm 4.8$ & $23.8 \pm 3.4$ & 0.053 \\
\hline Comorbidities & $19(54.3)$ & $207(56.6)$ & 0.465 \\
\hline Helicobacter pylori positivity & $23(65.7)$ & $255(69.7)$ & 0.378 \\
\hline Open type-AG & $2(5.7)$ & $60(16.4)$ & 0.068 \\
\hline Multiplicity & $4(11.4)$ & $34(9.3)$ & 0.429 \\
\hline Tumor location & & & 0.635 \\
\hline Upper third & $6(17.1)$ & 43 (11.7) & \\
\hline Middle third & $8(22.9)$ & $95(26.0)$ & \\
\hline Lower third & $21(60.0)$ & $228(62.3)$ & \\
\hline Carcinoma & $19(54.3)$ & $172(47.0)$ & 0.258 \\
\hline Submucosal invasion & $4(11.4)$ & $34(9.3)$ & 0.429 \\
\hline Ulceration & $1(2.9)$ & $21(5.7)$ & 0.409 \\
\hline Submucosal fibrosis & $8(22.9)$ & $36(9.8)$ & 0.026 \\
\hline Resected specimen size, cm & $4.2 \pm 1.7$ & $3.5 \pm 1.5$ & 0.017 \\
\hline Resected specimen area, $\mathrm{cm}^{2}$ & $15.6 \pm 13.8$ & $10.2 \pm 8.1$ & 0.001 \\
\hline Procedural time, min & $40.1 \pm 35.8$ & $25.5 \pm 23.6$ & 0.001 \\
\hline Coagulation time, min & $11.8 \pm 7.8$ & $8.1 \pm 5.9$ & 0.001 \\
\hline $\begin{array}{l}\text { Significant intraprocedural } \\
\text { bleeding }\end{array}$ & $10(28.6)$ & $89(24.3)$ & 0.353 \\
\hline Use of hemoclips during ESD & $10(28.6)$ & $48(13.1)$ & 0.018 \\
\hline Endoscopist & & & 0.571 \\
\hline Endoscopist 1 & $9(7.4)$ & 113 (92.6) & \\
\hline Endoscopist 2 & $26(9.3)$ & $253(90.7)$ & \\
\hline
\end{tabular}

Data are presented as mean \pm SD or number (\%).

BMI, body mass index; AG, atrophic gastritis; ESD, endoscopic submucosal dissection.

related bleeding compared with high-dose continuous pantoprazole infusion. Since pantoprazole at $40 \mathrm{mg} /$ day was insufficient for maintaining high gastric $\mathrm{pH},{ }^{27}$ we designed pantoprazole $40 \mathrm{mg}$ twice a day as a low-dose PPI treatment. Several studies support our findings. In a meta-analysis including four Korean and Japanese randomized controlled trials, the mean gastric $\mathrm{pH}$ before PPI administration was relatively high $(5.9 \pm 2.5){ }^{28}$ In countries with high prevalence of $H$. pylori infection, atrophic gastritis is common especially in patients with gastric epithelial neoplasm. As corpus atrophy causes loss of parietal cell mass, the stomach becomes hypochlorhydric, implying that a lower PPI dose is enough to maintain neutral gastric $\mathrm{pH}$. Oh et al. ${ }^{27}$ also reported that a pantoprazole regimen of $40 \mathrm{mg}$ twice a day is sufficient to maintain gastric $\mathrm{pH}>6.0$ in Korean patients with PUB or receiving gastric EMR. Recently, Choi et al. ${ }^{29}$ compared the effects of high-dose pantoprazole administered in continu-
Table 6. Results of the Univariate Analysis of Risk Factors for Delayed Bleeding (Later Than 48 Hours)

\begin{tabular}{|c|c|c|c|}
\hline Variable & $\begin{array}{c}\text { Delayed } \\
\text { bleeding } \\
(n=10)\end{array}$ & $\begin{array}{c}\text { No delayed } \\
\text { bleeding } \\
(\mathrm{n}=391)\end{array}$ & $\mathrm{p}$-value \\
\hline Age, yr & $66.0 \pm 6.7$ & $64.6 \pm 9.1$ & 0.617 \\
\hline Male sex & $7(70.0)$ & $267(68.3)$ & 0.605 \\
\hline BMI, $\mathrm{kg} / \mathrm{m}^{2}$ & $23.7 \pm 2.7$ & $23.6 \pm 3.6$ & 0.999 \\
\hline Comorbidities & $8(80.0)$ & $218(55.8)$ & 0.113 \\
\hline Helicobacter pylori positivity & $7(70.0)$ & $271(69.3)$ & 0.632 \\
\hline Open type-AG & $1(10.0)$ & $61(15.6)$ & 0.526 \\
\hline Multiplicity & $2(20.0)$ & $36(9.2)$ & 0.241 \\
\hline Tumor location & & & 0.070 \\
\hline Upper third & $2(20.0)$ & $47(12.0)$ & \\
\hline Middle third & $5(50.0)$ & $98(25.1)$ & \\
\hline Lower third & $3(30.0)$ & $246(62.9)$ & \\
\hline Carcinoma & $7(70.0)$ & $184(47.1)$ & 0.133 \\
\hline Submucosal invasion & $2(20.0)$ & $36(9.2)$ & 0.243 \\
\hline Ulceration & $1(10.0)$ & $21(5.4)$ & 0.435 \\
\hline Submucosal fibrosis & $0(0.0)$ & $44(11.3)$ & 0.308 \\
\hline Resected specimen size, cm & $5.3 \pm 3.2$ & $3.5 \pm 1.5$ & $<0.001$ \\
\hline Resected specimen area, $\mathrm{cm}^{2}$ & $18.2 \pm 13.7$ & $10.5 \pm 8.7$ & 0.007 \\
\hline Procedural time, min & $45.2 \pm 34.4$ & $26.3 \pm 24.7$ & 0.019 \\
\hline Coagulation time, min & $15.0 \pm 14.2$ & $8.2 \pm 5.8$ & 0.001 \\
\hline $\begin{array}{l}\text { Significant intraprocedural } \\
\text { bleeding }\end{array}$ & $3(30.0)$ & $96(24.6)$ & 0.466 \\
\hline Use of hemoclips during ESD & $1(10.0)$ & $57(14.6)$ & 0.563 \\
\hline Early bleeding & $1(10.0)$ & $34(8.7)$ & 0.603 \\
\hline High-risk stigmata on SLE & $1(10.0)$ & $34(8.7)$ & 0.603 \\
\hline Endoscopist & & & 0.180 \\
\hline Endoscopist 1 & $5(4.1)$ & 117 (95.9) & \\
\hline Endoscopist 2 & $5(1.8)$ & 274 (98.2) & \\
\hline
\end{tabular}

Data are presented as mean \pm SD or number $(\%)$.

BMI, body mass index; AG, atrophic gastritis; ESD, endoscopic submucosal dissection; SLE, second-look endoscopy.

ous infusion and bolus injection (40 mg twice a day), and concluded that PPI dosing methods did not affect the incidence of postprocedural bleeding.

Although intraprocedural bleeding is usually well-controlled, endoscopists sometimes encounter challenging situations. Uncontrolled profuse bleeding not only worsens the field of vision but also interferes with subsequent dissection. In our trial, we aimed to decrease gastric acidity at the time of ESD to minimize the risk of intraprocedural and early bleeding; for this purpose, we administered the first dose of pantoprazole at least 2 hours before ESD in both groups. To our knowledge, this is the first study investigating the effects of preprocedural PPI on intraprocedural bleeding; we noted that preprocedural pantoprazole dosing regimens did not influence the incidence of intraprocedural 
bleeding. In fact, intraprocedural bleeding is mainly affected by technical aspects such as the operators' experience, electrosurgical unit settings, type of electrosurgical knives, and injection solution. ${ }^{2,12,13}$ To minimize the risk for intraprocedural bleeding, operators should facilitate adequate exposure of the submucosal plane, and dissect at the appropriate depth beneath the ramified vascular network. Prophylactic electrocoagulation is necessary especially for penetrating vessels from the muscle layer. Besides procedural factors, the patient's age (younger), tumor location (upper and middle third), and tumor size $(\geq 3 \mathrm{~cm})$ have been reported as risk factors for intraprocedural bleeding., ${ }^{2,13-15}$ In our multivariate analysis, proximal tumor location, presence of fibrosis, submucosal invasion, and larger resected specimen size/ area were significant predictors of intraprocedural bleeding.

Many studies have investigated the risk factors for postESD bleeding, and the patient's age, tumor size, tumor location, macroscopic findings, histology findings, long operation time, and poor control of bleeding during ESD have been reported as factors associated with post-ESD bleeding. ${ }^{30}$ Our present findings agree that tumor size and resected specimen size represent critical factors. Although the longer coagulation time was related with post-ESD bleeding, we consider that it was not the cause of post-ESD bleeding but the consequence of resecting larger specimen. Careful endoscopic hemostasis and monitoring is needed for patients with a large iatrogenic ulcer. We found postprocedural bleeding rate of $11.0 \%$ with early bleeding rate of $8.7 \%$, which is relatively high compared with recently published data. However, the actual data is not different from those. As our study aimed to investigate detailed differences, we widely defined early bleeding, which included blood or clots in the stomach regardless of active bleeding and hemorrhage occurring during SLE. Indeed, most early bleeding events were minor which could be passed over in clinical practice. After excluding such minor events (five cases with gastric blood without active bleeding and 26 cases with bleeding occurring during SLE), the revised postprocedural bleeding rate was only 3.5\% with early bleeding rate of $1.0 \%$. In addition to PPI effects, these favorable outcomes could be explained by meticulous prophylactic coagulation. A previous study reported that prophylactic coagulation at the base of post-ESD ulcers decreased the rate of bleeding from $7.1 \%$ to $3.1 \% .{ }^{19}$ In recent, SLE for all patients who underwent gastric ESD is not usually recommended. In our study, SLE has caused even more bleeding events during the examination due to the mechanical irritation and aeration, and the preventive hemostasis on such minor bleeding was not really effective for reducing the delayed bleeding events.

Few reports have compared the effects of PPI administration regimen in preventing gastric ESD-related bleeding. In the present trial, we analyzed a largest series of samples than that investigated in previous studies, and additionally assessed the incidence of intraprocedural bleeding. However, our study has some limitations. First, we could not meet the statistical sample size though this is a largest study. Second, because we did not obtain the gastric $\mathrm{pH}$ level during ESD, we could not accurately know the direct effects on ESD-related bleeding according to different PPI dosing regimen. Third, as this is not a multinational study, it is difficult to generalize our results to other races or countries. However, patients with gastric epithelial neoplasm are more likely to have preneoplastic conditions such as atrophic gastritis or intestinal metaplasia, with higher probability of low levels of gastric acid. That is, potent acid inhibition might not be necessary in such patients, irrespective of race or geographical origin.

At present, many kinds of PPIs and diverse administration regimens are used, with no consensus regarding the optimal strategy for the management of gastric ESD-related bleeding. However, our results suggest that intermittent dosing of pantoprazole might be sufficient and cost-effective for the prevention of ESD-related bleeding compared to continuous infusion of pantoprazole. Operators should consider tumor characteristics when planning the ESD procedure to minimize the risk of intraprocedural bleeding. Furthermore, patients with a large iatrogenic ulcer should be carefully monitored, as the size of the iatrogenic ulcer is the most important factor predicting postprocedural bleeding.

\section{CONFLICTS OF INTEREST}

No potential conflict of interest relevant to this article was reported.

\section{ACKNOWLEDGEMENTS}

This study was supported via a Biomedical Research Institute Grant (2012-02) from Pusan National University Hospital.

\section{REFERENCES}

1. Oka S, Tanaka S, Kaneko I, et al. Advantage of endoscopic submucosal dissection compared with EMR for early gastric cancer. Gastrointest Endosc 2006;64:877-883.

2. Jeon SW, Jung MK, Cho CM, et al. Predictors of immediate bleeding during endoscopic submucosal dissection in gastric lesions. Surg Endosc 2009;23:1974-1979.

3. Jang JS, Choi SR, Graham DY, et al. Risk factors for immediate and delayed bleeding associated with endoscopic submucosal dissection of gastric neoplastic lesions. Scand J Gastroenterol 2009;44:1370-1376.

4. Ahn JY, Jung HY, Choi KD, et al. Endoscopic and oncologic outcomes after endoscopic resection for early gastric cancer: 1370 cases of absolute and extended indications. Gastrointest Endosc 2011;74:485-493.

5. Goto 0, Fujishiro M, Oda I, et al. A multicenter survey of the management after gastric endoscopic submucosal dissection related to 
postoperative bleeding. Dig Dis Sci 2012;57:435-439.

6. Toyokawa T, Inaba T, Omote S, et al. Risk factors for perforation and delayed bleeding associated with endoscopic submucosal dissection for early gastric neoplasms: analysis of 1123 lesions. J Gastroenterol Hepatol 2012;27:907-912.

7. Lim JH, Kim SG, Kim JW, et al. Do antiplatelets increase the risk of bleeding after endoscopic submucosal dissection of gastric neoplasms? Gastrointest Endosc 2012;75:719-727.

8. Toyonaga T, Man-i M, East JE, et al. 1,635 Endoscopic submucosal dissection cases in the esophagus, stomach, and colorectum: complication rates and long-term outcomes. Surg Endosc 2013;27:1000-1008.

9. Lim SM, Park JC, Lee H, Shin SK, Lee SK, Lee YC. Impact of cumulative time on the clinical outcomes of endoscopic submucosal dissection in gastric neoplasm. Surg Endosc 2013;27:1397-1403.

10. Ryu HY, Kim JW, Kim HS, et al. Second-look endoscopy is not associated with better clinical outcomes after gastric endoscopic submucosal dissection: a prospective, randomized, clinical trial analyzed on an as-treated basis. Gastrointest Endosc 2013;78:285294.

11. Goto 0, Fujishiro M, Kodashima S, et al. A second-look endoscopy after endoscopic submucosal dissection for gastric epithelial neoplasm may be unnecessary: a retrospective analysis of postendoscopic submucosal dissection bleeding. Gastrointest Endosc 2010;71:241-248.

12. Fujishiro M, Chiu PW, Wang HP. Role of antisecretory agents for gastric endoscopic submucosal dissection. Dig Endosc 2013;25 Suppl 1:86-93.

13. Oda I, Gotoda T, Hamanaka H, et al. Endoscopic submucosal dissection for early gastric cancer: technical feasibility, operation time and complications from a large consecutive series. Dig Endosc 2005;17:54-58.

14. Ahmad NA, Kochman ML, Long WB, Furth EE, Ginsberg GG. Efficacy, safety, and clinical outcomes of endoscopic mucosal resection: a study of 101 cases. Gastrointest Endosc 2002;55:390-396.

15. Ohkuwa M, Hosokawa K, Boku N, Ohtu A, Tajiri H, Yoshida S. New endoscopic treatment for intramucosal gastric tumors using an insulated-tip diathermic knife. Endoscopy 2001;33:221-226.

16. Yang Z, Wu Q, Liu Z, Wu K, Fan D. Proton pump inhibitors versus histamine-2-receptor antagonists for the management of iatrogenic gastric ulcer after endoscopic mucosal resection or endoscopic submucosal dissection: a meta-analysis of randomized trials. Digestion 2011;84:315-320.

17. Gotoda T, Yanagisawa A, Sasako M, et al. Incidence of lymph node metastasis from early gastric cancer: estimation with a large number of cases at two large centers. Gastric Cancer 2000;3:219-
225.

18. Gotoda T. A large endoscopic resection by endoscopic submucosal dissection procedure for early gastric cancer. Clin Gastroenterol Hepatol 2005;3(7 Suppl 1):S71-S73.

19. Takizawa K, Oda I, Gotoda T, et al. Routine coagulation of visible vessels may prevent delayed bleeding after endoscopic submucosal dissection: an analysis of risk factors. Endoscopy 2008;40:179183.

20. Forrest JA, Finlayson ND, Shearman DJ. Endoscopy in gastrointestinal bleeding. Lancet 1974;2:394-397.

21. Kimura K, Satoh K, Ido K, Taniguchi Y, Takimoto T, Takemoto T. Gastritis in the Japanese stomach. Scand J Gastroenterol Suppl 1996;214:17-20.

22. Brunner G, Luna P, Hartmann M, Wurst W. Optimizing the intragastric $\mathrm{pH}$ as a supportive therapy in upper GI bleeding. Yale $\mathrm{J}$ Biol Med 1996;69:225-231.

23. van Rensburg CJ, Hartmann M, Thorpe A, et al. Intragastric $\mathrm{pH}$ during continuous infusion with pantoprazole in patients with bleeding peptic ulcer. Am J Gastroenterol 2003;98:2635-2641.

24. Udd M, Töyry J, Miettinen P, Vanninen E, Mustonen H, Julkunen $R$. The effect of regular and high doses of omeprazole on the intragastric acidity in patients with bleeding peptic ulcer treated endoscopically: a clinical trial with continuous intragastric $\mathrm{pH}$ monitoring. Eur J Gastroenterol Hepatol 2005;17:1351-1356.

25. Gralnek IM, Dumonceau JM, Kuipers EJ, et al. Diagnosis and management of nonvariceal upper gastrointestinal hemorrhage: European Society of Gastrointestinal Endoscopy (ESGE) guideline. Endoscopy 2015;47:a1-a46.

26. Neumann I, Letelier LM, Rada G, et al. Comparison of different regimens of proton pump inhibitors for acute peptic ulcer bleeding. Cochrane Database Syst Rev 2013;(6):CD007999.

27. Oh JH, Choi MG, Dong MS, et al. Low-dose intravenous pantoprazole for optimal inhibition of gastric acid in Korean patients. J Gastroenterol Hepatol 2007;22:1429-1434.

28. Nishizawa T, Suzuki H, Akimoto T, et al. Effects of preoperative proton pump inhibitor administration on bleeding after gastric endoscopic submucosal dissection: a systematic review and metaanalysis. United European Gastroenterol J 2016;4:5-10.

29. Choi CW, Kang DH, Kim HW, et al. High dose proton pump inhibitor infusion versus bolus injection for the prevention of bleeding after endoscopic submucosal dissection: prospective randomized controlled study. Dig Dis Sci 2015;60:2088-2096.

30. Sugimoto M, Jang JS, Yoshizawa Y, et al. Proton pump inhibitor therapy before and after endoscopic submucosal dissection: a review. Diagn Ther Endosc 2012;2012:791873. 